\title{
Editorial
}

\section{(Pleasant) consequences of digital printing and other news}

Dear authors, readers and supporters,

As you know, in our Journal of Geosciences we strive to bring you scientific papers of both high technical and scientific standard. At the same time, we try to keep the expenses, both to the authors and to the Society, minimal. Therefore, we have been experimenting with digital printing for some time already and we believe now that the resulting quality is well comparable with the classical printing. In addition, the digital technology allows us to optimize the number of hardcopies produced, just printing the older issues on demand.

But there are even more pleasant consequences - the digital printing will enable us to revise and simplify the price list for colour printing - from the issue 3/2018, we shall charge mere 300 CZK/15 EUR/18 USD per colour page printed. For a single page, this represents a drop to almost one tenth of the former price. Moreover, colour illustrations intended solely for the online PDF are always free.

Lastly, the page charges of $500 \mathrm{CZK} / 20$ EUR, as introduced from the issue $1 / 2013$, remain unchanged. These still apply to every printed page exceeding the limit of sixteen, which is free for everyone. However, if the corresponding author is a paying member of the Czech Geological Society and the extended length is justified by the scientific merit, no extra fee is required.

The last change that you may have noticed is the substantial reconstruction of the Internal Editorial Board (the external one shall follow soon). This reflects the fact that very much the same team has worked hard since the new format of the Journal has been introduced, i.e. some for 11 years. Over this time, some of us got (re)tired, and everyone got much more exact knowledge what contributions and topics we have to deal with; even some brand new fields have emerged meanwhile.

I have to mention at this place a very sad loss we have suffered recently - Stanislav Vrána, the former editor-inchief of our predecessor, Journal of the Czech Geological Society, sadly has passed away on March 24, 2018, aged 82 years. We are sure that without his vision, energy, tireless editorial and organizational work, the Journal of Geosciences would certainly not exist... Requiescat in pace!

In Prague, April 2018

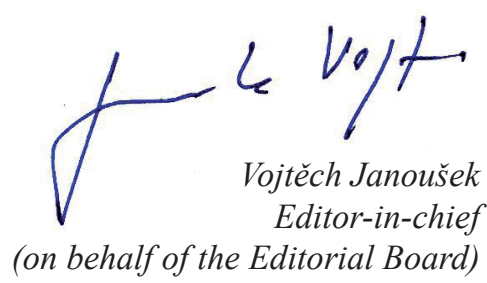

